\title{
Semicrystalline polythiophene-based nanoparticles deposited from water on flexible PET/ITO substrates as a sustainable approach towards long-lasting solid- state electrochromic devices
}

Tiago Moreira, ${ }^{a}$ César A.T. Laia, ${ }^{* a}$ Mariana Antunes, ${ }^{a}$ Francesca Di Maria, ${ }^{* b, c}$ Mattia Zangoli, ${ }^{\text {b,c }}$ Stefano De Monte, ${ }^{\mathrm{e}}$ Fabiola Liscio, ${ }^{\mathrm{d}}$ A. Jorge Parola, ${ }^{\mathrm{a}}$ Giovanna Barbarella ${ }^{\mathrm{b}, \mathrm{c}}$

${ }^{a}$ LAQV-REQUIMTE, Departamento de Química, Faculdade de Ciências e Tecnologia, Universidade NOVA de Lisboa, 2829-516 Caparica, Portugal.

${ }^{b}$ CNR-ISOF, ${ }^{c}$ Mediteknology srl and ${ }^{d}$ CNR-IMM, Area Ricerca CNR, Via P. Gobetti 101, 41100-Bologna, Italy

e A.P.E. Research, Area Science Park Basovizza, 34012 Trieste, Italy

\section{cat1@,fct.unl.pt and francesca.dimaria@isof.cnr.it}

\begin{abstract}
We report the use of films of poly(3-hexylthiophene-2,5-diyl), P3HT, nanoparticles (NPs) prepared with the reprecipitation method employing water as solvent in the absence of surfactants for solid-state electrochromic devices (ECDs) and prove that these displays present enhanced properties when compared to similar ECDs with thin-films deposited from chloroform. Films of differently sized nanoparticles (100 to $400 \mathrm{~nm}$ ) were prepared and spray-coated on flexible PET-ITO substrates and tested for electrochromic properties. Using films of nanoparticles with $100 \mathrm{~nm}$ of diameter, electrochromic devices with switching times ( $\left.\mathbf{t}_{\mathbf{9}}\right)$ of 4 seconds were achieved while electrochromic devices using P3HT thin-film presented switching speeds of 13 seconds for reduction (bleached to colored state). Additionally, the devices were subjected to 1000 cycles using $-1.5 \mathrm{~V} / 1.5 \mathrm{~V}$ and the displays using P3HT 100nm NPs presented higher transmittances $\left(\Delta \mathrm{T} / \mathrm{T}_{\mathrm{ox}}= \pm \mathbf{5 0} \%\right)$ when compared with devices with P3HT thin-film due to a more efficient oxidation step. Our data show that the availability of colloidal nanoparticles made of conjugated polymers deposited from water is an environmentally sustainable strategy leading to electrochromic devices with improved properties.
\end{abstract}

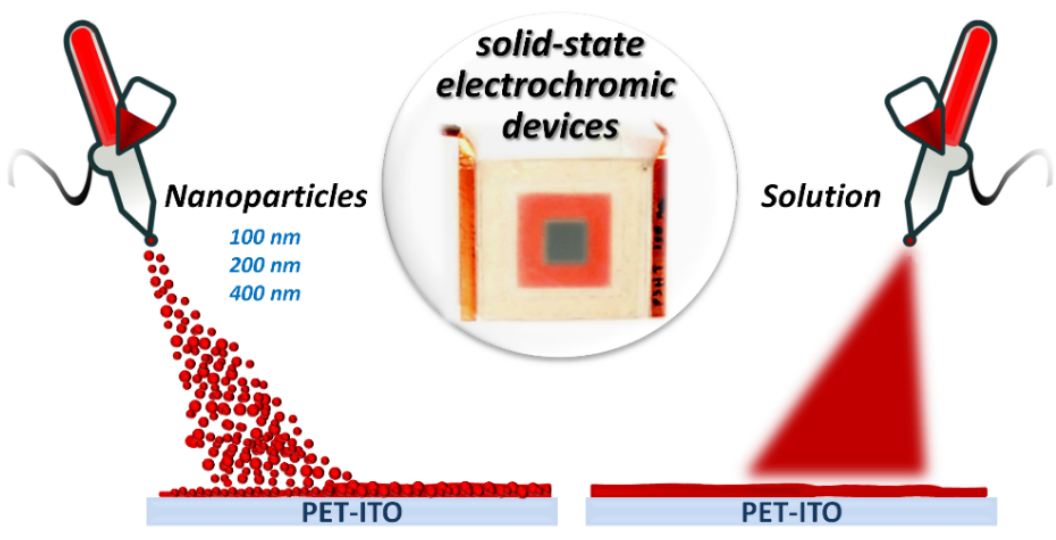




\section{INTRODUCTION}

Since the pioneering work of Deb in $1967,{ }^{1}$ the use of different redox states to control color became crucial for the development of intelligent windows for energy and light management of buildings or transportation (e.g., rearview mirrors). ${ }^{2-4}$ Metal oxides (e.g., $\mathrm{WO}_{3}$ ) and organic molecules such as methyl viologens are at the core of the commercial use of this technology. In the meantime, semiconductor polymers were discovered in $1979,{ }^{5,6}$ which prompted a wave of research about their optical properties. Heeger and co-workers discussed this, with special attention given to polythiophenes due to their relatively low toxicity and relatively simple synthesis. However, only in 1994, a first electrochromic effect was reported for PEDOT, ${ }^{7-9}$ which is still today the most used polymer in electrochromic devices. This was followed by a strong synthetic effort to tune polythiophene optical properties and solubility. ${ }^{10-15}$ Yet, while metal oxides could be deposited in a variety of ways including nanopatterning ${ }^{16}$ to ensure faster kinetics and efficiencies for utilization in smart windows, only the mixture of PEDOT and PSS is a true commercial alternative to inorganic materials. ${ }^{10}$ This is because PEDOT/PSS is water dispersible and their thin-films have a high electrical conductivity.

Currently, there is great interest in flexible electrochromic devices and their numerous applications spanning innovative fields such as adaptive camouflage, wearable and deformable electronics, to the more futuristic information signage and electronic skin. ${ }^{17,18}$ In parallel, expectations are increasing for green approaches to film formation in solid-state devices that would not require expensive optimization of deposition techniques, search for non-toxic solvents or additives addition. Very recently, application of nanostructures of semiconductor polymers in electrochromic devices started to emerge and various methods of fabricating conducting polymer nanopatterned electrodes were described. ${ }^{19-21}$ Nanostructures are expected to favor, for example, charge transport by virtue of the increase in contact area between the electrodes and the electrolyte and consequently to affect important parameters such as color contrast or response time. ${ }^{22,23}$ In this framework, electrochromism based on semiconducting conjugated polymers plays a very important role. Most commercial applications of electrochromism are indeed focused on $\pi$-conjugated organic polythiophene polymers such as the widely studied poly-3,4-alkyldioxythiophenes ${ }^{24,13}$ displaying electrochemical stability, electrical conductivity and chemical versatility towards the extension of color palette through structural modifications. Other polythiophenes have also been explored, such as poly-3hexylthiophene-2,5-diyl, P3HT - one of the most studied conjugated polymers as a case polymer for the study of optoelectric properties on, e.g., electrochromic devices and optically switchable transistors. ${ }^{25,26,27} \mathrm{P} 3 \mathrm{HT}$ is soluble in organic solvents such as chloroform but not in water, the most 
environmentally friendly of all solvents. However, the polymer can be prepared in the form of nanoparticles as a stable aqueous suspension and deposited as thin film from an aqueous-phase. ${ }^{21,28}$

Here we show that P3HT prepared as stable aqueous suspensions of nanoparticles through the surfactant-free reprecipitation method ${ }^{29}$ behaves as an ink that can be easily deposited on flexible PET-ITO electrodes via spray-casting. We prove that Nps with size of $100 \mathrm{~nm}$ present enhanced properties when compared to similar ECDs with larger NPs and thin-films deposited from chloroform.

\section{EXPERIMENTAL SECTION}

Synthesis of polymers. Poly(3-hexylthiophene-2,5-diyl), P3HT, was synthesized by oxidative polymerization of 3-hexyl-thiophene with ferric chloride as already reported. ${ }^{30}$ As a test of the possibility to expand the results obtained for P3HT to other polythiophenes, a novel polymer - poly(4(3',4-bis((2-ethylhexyl)oxy)-5'-methyl-[2,2'-bithiophen]-5-yl)-7-methylbenzo[c]thiophene, PORwas also synthesized. The molecular structure, the detailed synthesis, the electrochromic properties, the preparation of the corresponding NPs and initial data concerning ECDs made using a $200 \mathrm{~nm}$ NPs film are reported in supporting information.

\section{Synthesis of nanoparticles.}

Synthesis of P3HT nanoparticles. Colloidal solutions of P3HT nanoparticles (P3HT NPs) have already been described. ${ }^{21,28}$ To avoid the presence of any surfactant, we prepared P3HT NPs by the reprecipitation method, ${ }^{29}$ using a small portion of P3HT dissolved in pure THF which was added dropwise to miliQ water under vigorous stirring (see Scheme S1). The size of the final nanoparticles was selected by differential centrifugation. ${ }^{29}$ Dynamic Light Scattering (DLS) was performed in order to characterize the size of the nanoparticles (see SI).

The P3HT polymer, as well as the corresponding nanoparticles, were deposited on the PET-ITO electrodes by the spray-casting method. The PET-ITO substrates were placed over a heating plate at $60{ }^{\circ} \mathrm{C}$ ( $\mathrm{P} 3 \mathrm{HT}$ polymer dissolved in $\mathrm{CHCl}_{3}$ ) or $90^{\circ} \mathrm{C}$ (P3HT nanoparticles dispersed in miliQ water). The P3HT formulations were then spray-casted on the electrodes and dried in the heating plate for 1 minute between each layer. The P3HT printed solutions had a $5 \mathrm{mg} / \mathrm{ml}$ concentration, in chloroform, while the nanoparticles dispersion concentration varied depending on the nanoparticle size $(1 \mathrm{mg} / 7 \mathrm{ml}$ to $5 \mathrm{mg} / 7 \mathrm{ml}$, in miliQ water). Grazing Incidence X-ray Diffraction measurements (GIXRD) were performed on P3HT NPs deposited on silicon wafer. The 2D-GIXRD images were recorded at the XRD1 beamline at the Elettra synchrotron facility at Trieste (Italy) using a monochromatic beam with a wavelength of $1 \AA$. The incident angle of the X-ray beam, $\alpha_{i}$, was chosen $0.15^{\circ}$, in order to probe 
the crystal structure of the whole sample. The scattering patterns were recorded using a $2 \mathrm{D}$ camera (Pilatus detector) placed normal to the incident beam direction.

The produced electrochromic devices (ECD) were assembled using the following structure: PET-ITO / Polymer or NPs / Electrolyte / Polymer or NPs / ITO-PET. The assembly of these electrochromic devices was performed by producing the two substrates of PET-ITO with the material deposited and then closing them together face-to-face using a double-taped adhesive in order to avoid short-circuits between the two PET-ITO substrates. The electrolyte was deposited by hand filling the "pool" using the amount calculated accordingly to the volume needed to fill the final ECD. The electrolyte used was a $\mathrm{Li}^{+}$based UV curable electrolyte denominated Ynv.El. ${ }^{\circledR}$ property of Ynvisible ${ }^{\circledR}$ with the patent $\mathrm{n}^{\mathrm{o}}$ 20140361211. The absorption spectra of the ECD's (at different potentials) were run in a Cary 5000 UV-Vis-NIR spectrophotometer coupled to an Autolab PGSTAT 100N potentiostat. The range of potentials used varied from $-1.5 \mathrm{~V}$ for reduction and $1.5 \mathrm{~V}$ for oxidation. Switching time measurement involves a pre-treatment of 15 cycles with 5 seconds at each potential, followed by 3 cycles with 60 seconds for oxidation and reduction while the charge consumed by the ECD's was calculated from the current (in Amperes) developed during the switching time of the experiment. The charge consumed is used to calculate the coloration efficiency (CE) accordingly to the change of color (in absorbance) using the $\mathrm{CE}$ equation. ${ }^{3}$ The cycling experiments of the devices were made in a cycling box. Attached to this cycling box is a function generator to apply the desired potential, $-1.5 \mathrm{~V}$ $/ 1.5 \mathrm{~V}$ in a squared function. The $\mathrm{L}^{*} \mathrm{a} * \mathrm{~b} *$ coordinates are generated by MatLab functions created by the company Ydreams ${ }^{\circledR}$ from conversion of RGB coordinates using a ColorChecker ${ }^{\circledR}$, as reference. Synthesis of POR nanoparticles. In this polymer, however, nanoprecipitation in water does not give rise to stable colloidal dispersions. We then decided to test ethanol, which has a lower polarity, and this approach was successful. Ethanol is still a green solvent, much safer than chloroform or toluene. In terms of optical features, this polymer has a much lower bandgap when compared with and as an emission in the NIR region (Table S2).

\section{RESULTS AND DISCUSSION}

NPs optical properties, morphology and devices. Table 1 shows the optical properties of P3HT nanoparticles in water dispersions. For comparison, Table 1 also presents the absorption and emission properties of P3HT in a chloroform solution. While P3HT in chloroform shows a broad unstructured absorption band, assigned to a $\pi, \pi^{*}$ transition peaking at about $430 \mathrm{~nm}$, the P3HT nanoparticles in water show structured absorption spectra (Figure 1A) that shift to the red with increasing NPs size. Furthermore, the increase of the NPs size induces a change in the vibronic progression resulting in an enhancement of the low energy shoulder, which is indicative of increased 
intermolecular interactions between P3HT chains. ${ }^{31}$ Fluorescence spectra of the nanoparticles resemble those previously reported for P3HT thin-film (Figure $1 \mathrm{~A}){ }^{32}$ however, they are not dependent on NPs size suggesting similar emitting regions in the nanostructures regardless of their sizes. According to Spano et. al., the modifications observed both in absorption and emission spectra support the formation of aggregates with H-type arrangement, i.e. face to face orientation of the P3HT chains. ${ }^{33}$ Notably, the absorption and emission spectra of the pre-aggregate structure remain preserved when processed into thin films (Figure 1B), thus allowing the fabrication of active layers with defined/reproducible optoelectronic properties independently of the processing steps.

Table 1 - Optical properties of P3HT nanoparticles in water dispersions.

\begin{tabular}{|c|c|c|c|c|c|}
\hline & $\begin{array}{c}\lambda_{\mathrm{Abs}}{ }^{\max } \\
(\mathrm{nm})\end{array}$ & $\begin{array}{c}\lambda_{\mathrm{em}}^{\max } \\
(\mathbf{n m})\end{array}$ & $\begin{array}{c}\text { Stokes } \\
\text { Shift (eV) }\end{array}$ & $\begin{array}{c}\mathbf{E}_{\mathrm{g}} \\
(\mathrm{eV})\end{array}$ & $\phi_{\mathrm{f}}(\%)$ \\
\hline $\begin{array}{l}\mathrm{P} 3 \mathrm{HT} \text { in } \\
\mathrm{CHCl}_{3}\end{array}$ & 430 & 577 & 0.73 & 2.33 & 21.8 \\
\hline 100 & 499 & 722 & 0.77 & 1.92 & 0.45 \\
\hline 200 & 516 & 721 & 0.68 & 1.88 & 0.57 \\
\hline 400 & 541 & 721 & 0.57 & 1.80 & —(a) \\
\hline
\end{tabular}

(a) High scattering dispersion.

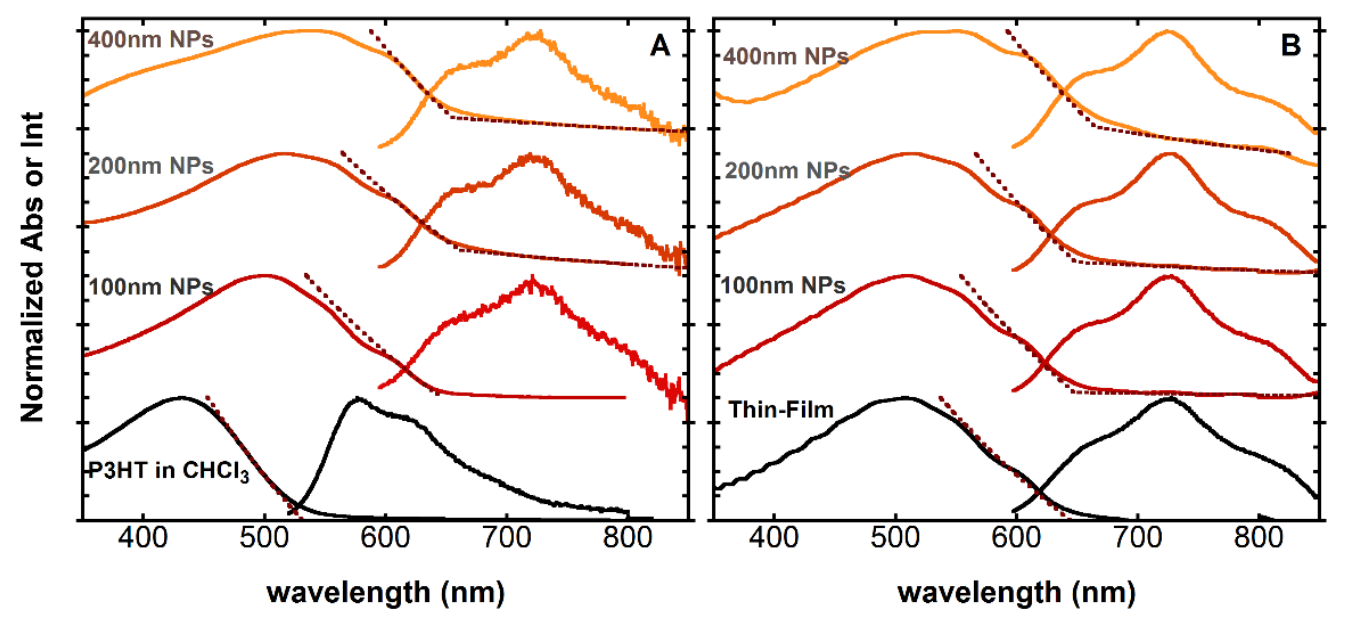

Figure 1. (A) Absorption and emission spectra of $\mathrm{P} 3 \mathrm{HT}$ in chloroform solution (black) and of 100nm (red), $200 \mathrm{~nm}$ (orange) and $400 \mathrm{~nm}$ (light orange) P3HT NPs as water dispersions. (B) In situ absorption and emission spectra of P3HT as film in assembled ECD, where the film was prepared from P3HT chloroform solution (black); 100nm (red), $200 \mathrm{~nm}$ (orange) and $400 \mathrm{~nm}$ (light orange) P3HT NPs as water dispersions. Emission spectra obtained with excitation wavelength at $550 \mathrm{~nm}$ for all devices. Dashed lines represent linear extrapolation to obtain the polymer bandgap. 
The presence of crystalline domains in the NPs is confirmed by Grazing-Incidence Wide-Angle Xray Scattering (GIWAXS) measurements of different sized P3HT NPs spray-coated on silicon support.
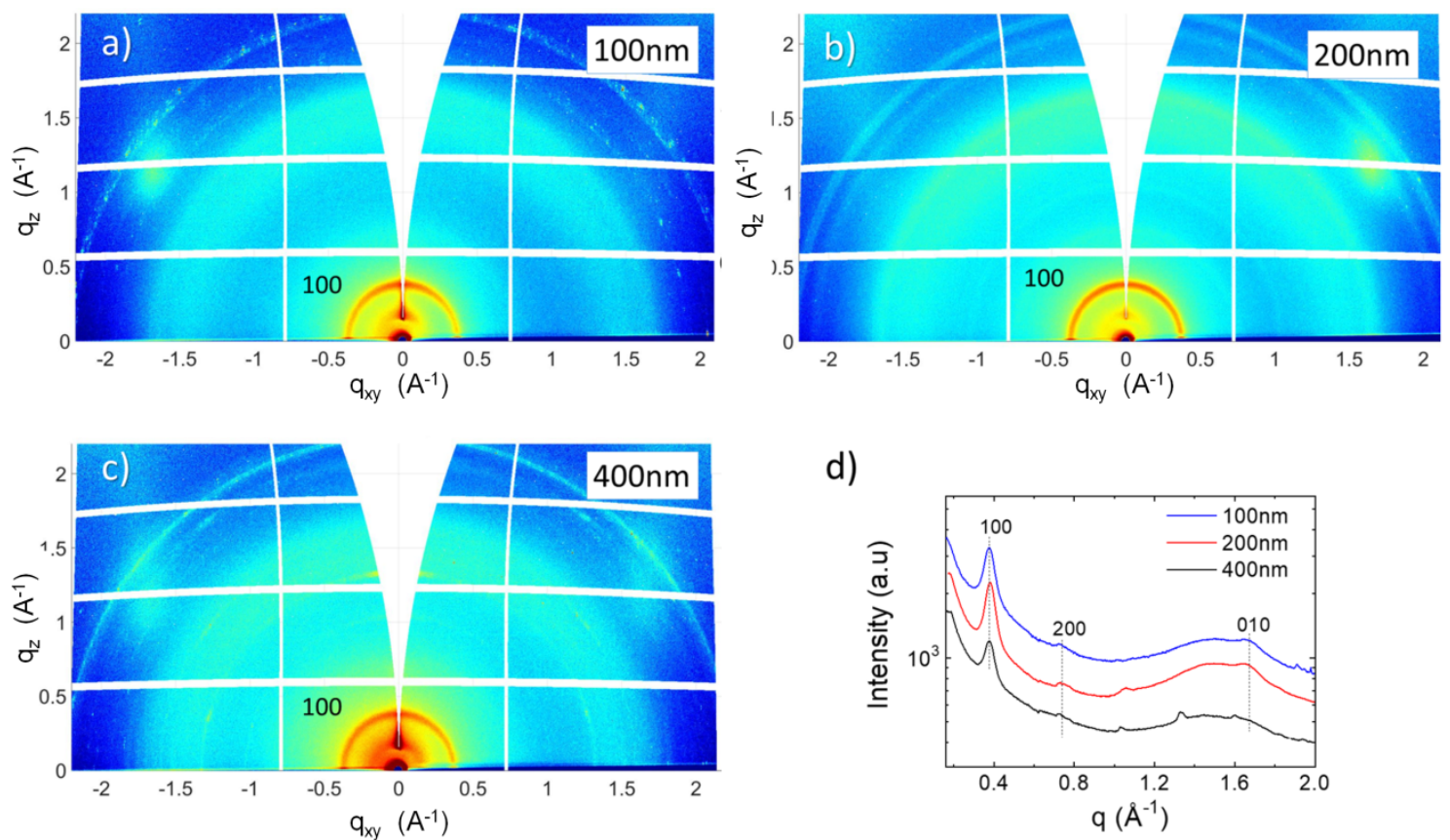

d)

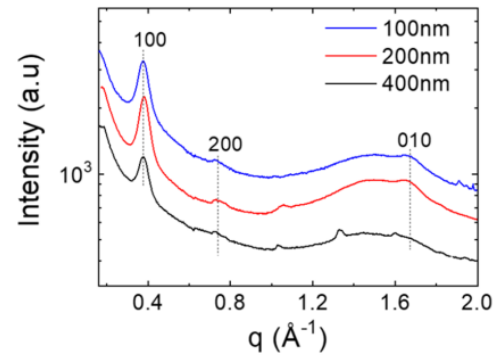

Figure 2. 2D-GIXRD images of different-sized P3HT NPs spray-coated on silicon support (a-c) and radially integrated intensity of the corresponding GIWAXS images (d).

The GIWAXS technique, indeed, allows the characterization of thin films structure determining the presence or absence of crystalline structures and probing the orientation of crystalline domains. 2D-GIWAXS images, collected for NPs of 100, 200, and $400 \mathrm{~nm}$ size, are reported in Figure 2 a-c. They show several rings indicating the presence of crystalline domains randomly oriented, regardless of the NPs size. The radially integrated intensity curves, extracted from the corresponding images, point out the characteristic (100) and (010) reflections coming from the lamellar and $\pi-\pi$ stacking (Figure 2d). Noteworthy, the presence of the (010) reflection confirms the presence of H-type aggregates, in agreement with optical measurements.

The dimension of the crystalline domains (L) has been evaluated from the (100) peak width, using the Scherrer-formula ${ }^{34}$ and taking into account the beam footprint ${ }^{35} \mathrm{~L}$ slightly increases from $12 \mathrm{~nm}$ to $14.6 \mathrm{~nm}$ when NPs size increases from $100 \mathrm{~nm}$ to $400 \mathrm{~nm}$. Moreover, a broad peak is also detectable in the range of 1.2-1.7 $\AA^{-1}$, indicating the presence of amorphous regions too. Figure S3 compares the specular XRD scans collected for thin film of P3HT spray-coated on silicon and a film obtained from spray-coating P3HT NPs of $100 \mathrm{~nm}$ size. It highlights that the P3HT film is more crystalline than the P3HT NPs film. 
We assembled several electrochromic devices using different P3HT nanoparticles batches. A comparison was always made with films that were cast by spray-drying from P3HT solutions in chloroform (hereafter called "thin films") and films cast by spray-drying from P3HT nanoparticles suspensions in water (hereafter called "NPs films"). We estimate the film's thickness by measuring the absorption spectra and calculating it from the Abs value at $550 \mathrm{~nm}$ using the reported value of the extinction coefficient. ${ }^{36}$ The performance was evaluated through spectroelectrochemistry measurements and CIE L*a*b color coordinates. ${ }^{22,23,37-39}$ From the user point-of-view, the difference from using chloroform or water-based inks is enormous in terms of health safety. Special care is necessary for the depositions from organic solvents in order to ensure not breathing toxic vapors in the process, while water dispersions completely avoid organic solvent vapors, making also this process much more comfortable. This is an important requirement for future applications, especially for do-it-yourself electrochromic kits designed for users without any pre-determined skills, while using eco-friendly materials with low environmental impact.
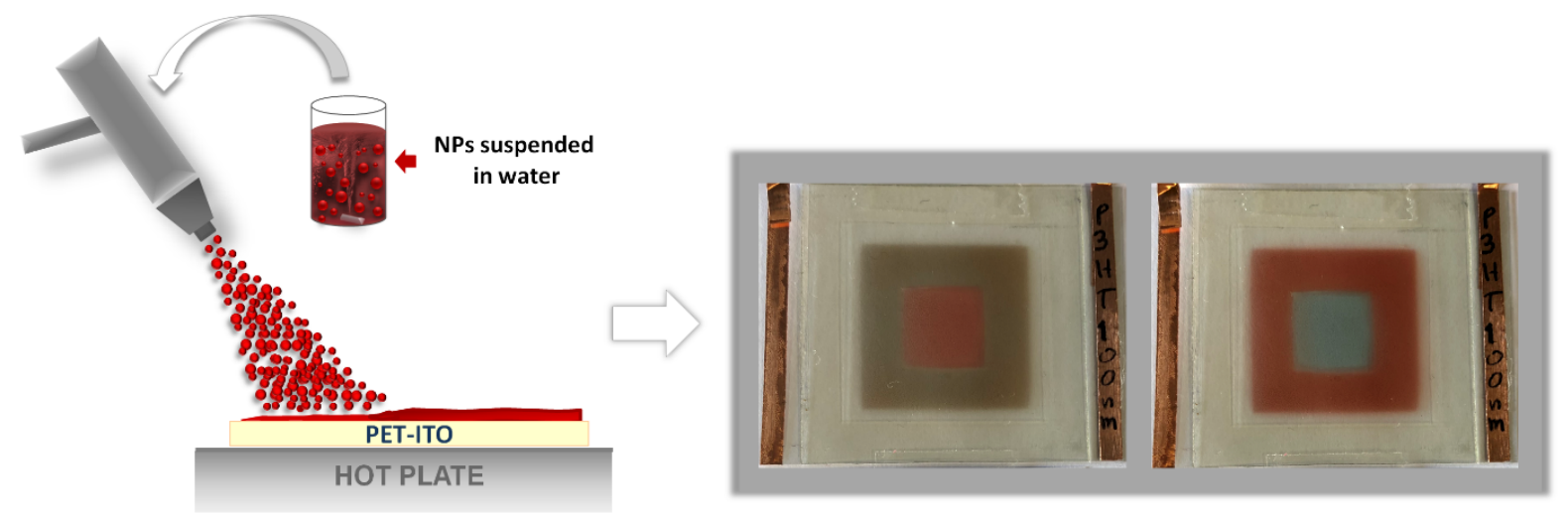

Figure 3. Electrochromic device with spray-coated $100 \mathrm{~nm}$ P3HT nanoparticles at different redox states. Inner square Reduced (Left) and Oxidized (Right). See video in Supporting Information.

Optical spectroscopy of the films cast from P3HT NPs water dispersion in the ECD shows the same features as in the dispersion itself (Figure 1B). There are slight shifts in the absorption maxima, but with a magnitude close to experimental error (Table 2). The largest difference, as expected, is between $\mathrm{P} 3 \mathrm{HT}$ in $\mathrm{CHCl}_{3}$ solution and the thin-films obtained from that solution. The absorption spectra acquire vibrational structure and become similar to the NPs films with a bandgap of about $1.92 \mathrm{eV}$ (as comparison, $1.89 \mathrm{eV}$ was obtained for regioregular P3HT films ${ }^{32}$ ). Fluorescence spectra are similar in all films, with almost no shifts observed, and matching those obtained for the nanoparticles dispersed in solution. Emitting states seem to be the same regardless if we have nanoparticles or films inside the ECDs. The matching of the optical properties of the nanoparticles is 
also a strong indication that their shape remains after deposition and assembly of the ECD. In Table 2, we also report the oxidation onset potentials and HOMO-LUMO energy levels (see also Figure $\mathrm{S} 4)$. In solution, the $\mathrm{E}_{\mathrm{HOMO}}$ for P3HT was previously measured $\left(-5.41 \mathrm{eV}^{40}\right)$ so the films clearly show an increase in the HOMO energy level and only a slight increase in the LUMO level.

Table 2 - Optical and redox properties of P3HT materials spray-cast in PET/ITO substrates.

\begin{tabular}{|c|c|c|c|c|c|c|c|}
\hline Sample & $\begin{array}{c}\lambda_{\mathrm{Abs}}^{\max } \\
(\mathrm{nm})\end{array}$ & $\begin{array}{c}\lambda_{\mathrm{em}}^{\max } \\
(\mathbf{n m})\end{array}$ & $\begin{array}{c}\text { Stokes } \\
\text { Shift (eV) }\end{array}$ & $\begin{array}{c}\mathbf{E}_{\mathrm{g}} \\
(\mathrm{eV})\end{array}$ & $\begin{array}{l}E^{\text {onset }} \text { ox } \\
(V){ }^{(c)}\end{array}$ & $\begin{array}{c}\mathbf{E}_{\text {номо }} \\
(\mathrm{eV})\end{array}$ & $\begin{array}{c}\text { ELUMC }_{\text {LuV }} \\
(\mathrm{eV})\end{array}$ \\
\hline Thin-film $^{(a)}$ & 510 & 731 & 0.74 & 1.92 & 0.53 & -4.93 & -3.02 \\
\hline $100 \mathrm{~nm} \mathrm{NPs}^{(\mathrm{b})}$ & 511 & 731 & 0.73 & 1.91 & 0.50 & -4.90 & -3.00 \\
\hline 200nm NPs ${ }^{(b)}$ & 514 & 731 & 0.72 & 1.90 & 0.50 & -4.90 & -2.99 \\
\hline 400nm NPs ${ }^{(b)}$ & 551 & 727 & 0.54 & 1.86 & 0.52 & -4.92 & -3.06 \\
\hline \multicolumn{8}{|c|}{ (a) Deposition of $\mathrm{P} 3 \mathrm{HT}$ from $\mathrm{CHCl}_{3}$ solutions. } \\
\hline Deposition & . & & & & & & \\
\hline
\end{tabular}

The P3HT electrochromic devices show color transitions between red and light blue (see pictures in Figure 3). All devices made from P3HT NPs or P3HT solutions in chloroform are capable of reversible electrochromic transitions by applying $-1.5 / 1.5 \mathrm{~V}$, with general properties resembling those previously reported for P3HT when deposited via other methods (such as electropolymerization). Here, however, the deposition is via a facile and safe method which in the future may be validated for, e.g., inkjet printing.
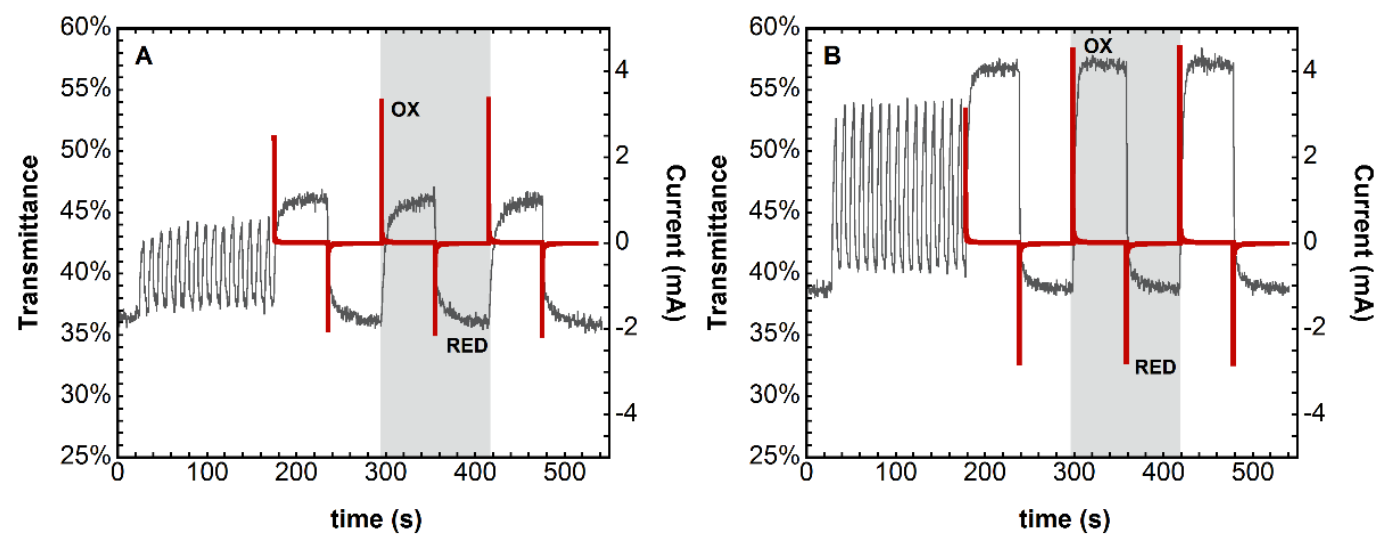

Figure 4 - (A) Transmittance (black) and current (red) data obtained from the characterization of the device using P3HT as thin-film. (B) Transmittance (black) and current (red) data obtained from the characterization of the device using P3HT $100 \mathrm{~nm}$ nanoparticles. 
We performed absorption and electric current measurements for all assembled devices. Figure 4 shows an experimental example, where the shadowed region is the selected data for further analysis (calculations of switching times and coloration efficiency).

Spectroelectrochemistry reveals that upon oxidation bands in the Near Infra-Red appear (NIR, Figure 5) which we assign to charge-transfer transitions with polaronic character (Polaronic CT bands). ${ }^{6}$ This is synchronized with the decrease of intensity of the $\pi, \pi^{*}$ transition in the visible region for voltages above $0 \mathrm{~V}$. The insertion of positive holes leads to polaronic states that evolve with the positive doping. Bands circa $750 \mathrm{~nm}$ appear and gradually become predominant with some blue shift for higher voltages. We observe these features in all devices, regardless of the nanoparticles size or if P3HT was spray-cast from chloroform solutions.
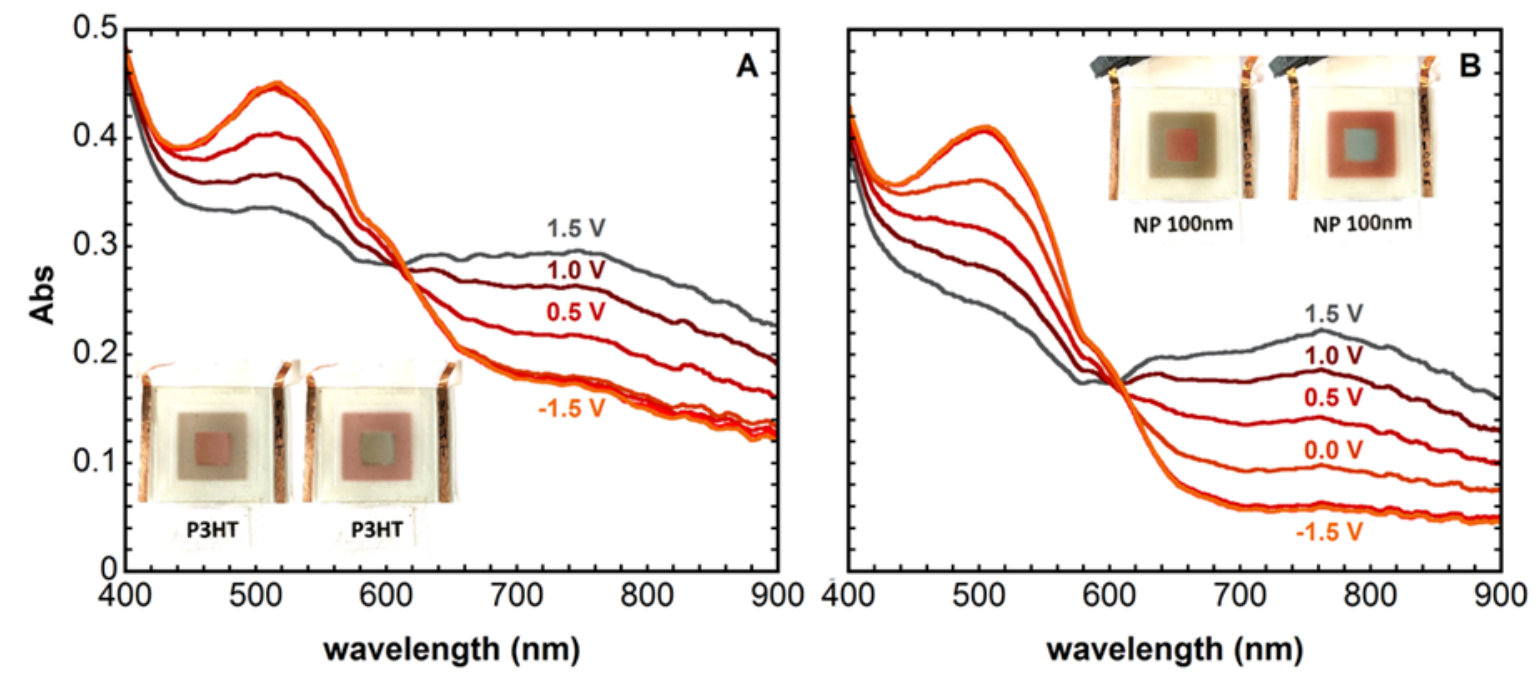

Figure 5 - (A) Spectroelectrochemistry measurement performed on the device using P3HT as thin-film spray-coated from chloroform. (B) Spectroelectrochemistry measurement performed on the device using P3HT P3HT 100nm nanoparticles. Both experiments were performed using 1.5, 1, 0.5, 0, - $0.5,-1$ and $-1.5 \mathrm{~V}$ with 1 min stabilization of the device at each potential before spectral acquisition.

Switching cycles show sharp electrochromic transitions for all devices as recorded by changes in the absorption spectra. We calculated figures of merit from all experimental data to evaluate ECD performance (Figure 6 and Table 3$),{ }^{43}$ such as:

i) $\mathbf{Q}_{\text {Red }}$ is the total charge consumed in coloration (or reduction),

ii) Qox is the total charge consumed in bleaching (or oxidation),

iii) $\mathbf{C E}$ is the coloration efficiency,

iv) $t_{90}$ is time required to reach a $90 \%$ change of transmittance $\left(0.9 \Delta \mathrm{T}_{\max }\right)$ for both oxidation $\left(\mathbf{t}_{90}{ }^{\mathbf{O x}}\right)$ and reduction $\left(\mathbf{t}_{90}{ }^{\text {Red }}\right) .{ }^{44}$ 
These values were obtained for a specific wavelength. In this case, the chosen wavelength is $510 \mathrm{~nm}$ where optical contrast is stronger for P3HT. The $t_{90}$ is calculated using the method recently described by Hassab et $a l .{ }^{44}$ In this method, the transmittance of the device versus time is fitted with an exponential relaxation, in such a way that it will be equal to $2.3 \tau$ (where $\tau$ is the relaxation time of the exponential function). $\mathrm{CE}$ is calculated at $\mathrm{t}_{90}{ }^{\mathrm{Red}}$ as $\Delta \mathrm{Abs} / \mathrm{Q}$ at that specific time. All values on Table 3 are averages of the 3 cycles (see Figure 4) and the errors are one standard deviation.

Table 3 - Transmittance $\left(\mathbf{T}_{\mathbf{R e d}}, \mathbf{T}_{\mathbf{O x}}\right)$, optical contrast $\left(\Delta \mathbf{T} / \mathbf{T}_{\mathbf{O x}}\right)$, charge consumption $\left(\mathbf{Q}_{\text {Red }}, \mathbf{Q}_{\mathbf{o x}}\right)$, switching time $\left(\mathbf{t}_{\mathbf{9 0}}{ }^{\mathbf{R e d}}, \mathbf{t}_{\mathbf{9 0}}{ }^{\mathbf{O} x}\right)$ and coloration efficiency $(\mathbf{C E})$ values calculated for the Thin-film and $100 \mathrm{~nm}$ NPs devices as prepared and after 1000 cycles using $-1.5 \mathrm{~V}$ and $1.5 \mathrm{~V}(1 \mathrm{cycle}=10 \mathrm{~s})$.

\begin{tabular}{|c|c|c|c|c|c|c|c|c|}
\hline EC & $\begin{array}{l}T_{\text {Red }} \\
(\%)\end{array}$ & $\begin{array}{l}\text { Tox }_{\text {Ox }} \\
(\%)\end{array}$ & $\begin{array}{c}\Delta \mathrm{T} / \mathrm{T}_{\mathbf{O x}} \\
(\%)\end{array}$ & $\begin{array}{l}Q_{\text {Red }} \\
(\mathrm{mC})\end{array}$ & $\begin{array}{l}\text { Qox } \\
(\mathrm{mC})\end{array}$ & $\begin{array}{l}t_{90}{ }^{\text {Red }} \\
(s)\end{array}$ & $\begin{array}{r}\mathrm{t}_{90}{ }^{\mathrm{Ox}} \\
(\mathrm{s})\end{array}$ & $\begin{array}{c}\mathrm{CE} \\
\left(\mathrm{C}^{-1} \cdot \mathrm{cm}^{2}\right)\end{array}$ \\
\hline
\end{tabular}

As prepared

\begin{tabular}{ccccccccc}
\hline Thin-film & $36.3 \pm 0.1$ & $46.6 \pm 0.2$ & $21.7 \pm 1.3$ & $-0.76 \pm 0.02$ & $0.87 \pm 0.03$ & $13.4 \pm 0.9$ & $11.4 \pm 3.1$ & $124 \pm 3$ \\
100nm NPs & $38.7 \pm 0.1$ & $57.8 \pm 0.1$ & $32.4 \pm 0.5$ & $-0.81 \pm 0.02$ & $1.18 \pm 0.01$ & $4.4 \pm 0.6$ & $6.0 \pm 0.2$ & $180 \pm 2$ \\
\hline
\end{tabular}

After 1000 cycles

\begin{tabular}{ccccccccc} 
Thin film & $33.2 \pm 0.4$ & $49.3 \pm 1.2$ & $30.9 \pm 1.9$ & $-0.82 \pm 0.03$ & $0.94 \pm 0.03$ & $9.2 \pm 1.0$ & $9.7 \pm 1.4$ & $162 \pm 3$ \\
100nm NPs & $33.6 \pm 1.5$ & $67.3 \pm 2.0$ & $46.6 \pm 1.1$ & $-1.35 \pm 0.04$ & $1.41 \pm 0.03$ & $3.8 \pm 0.4$ & $4.2 \pm 0.3$ & $161 \pm 3$ \\
\hline
\end{tabular}
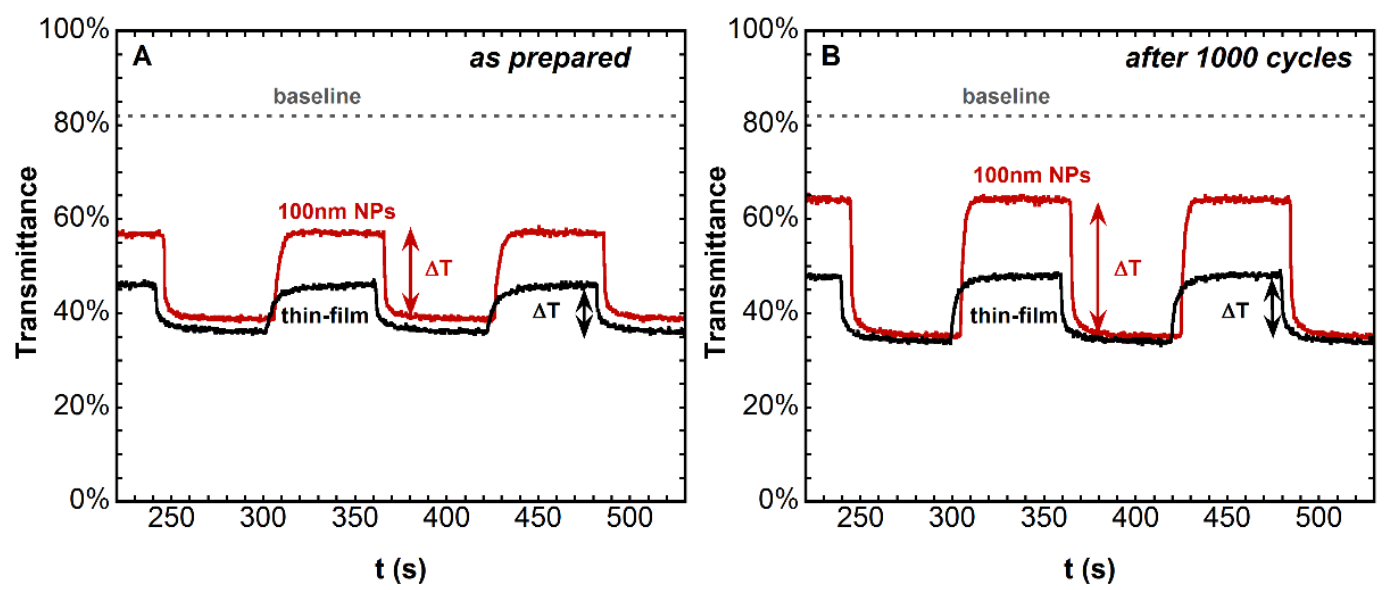

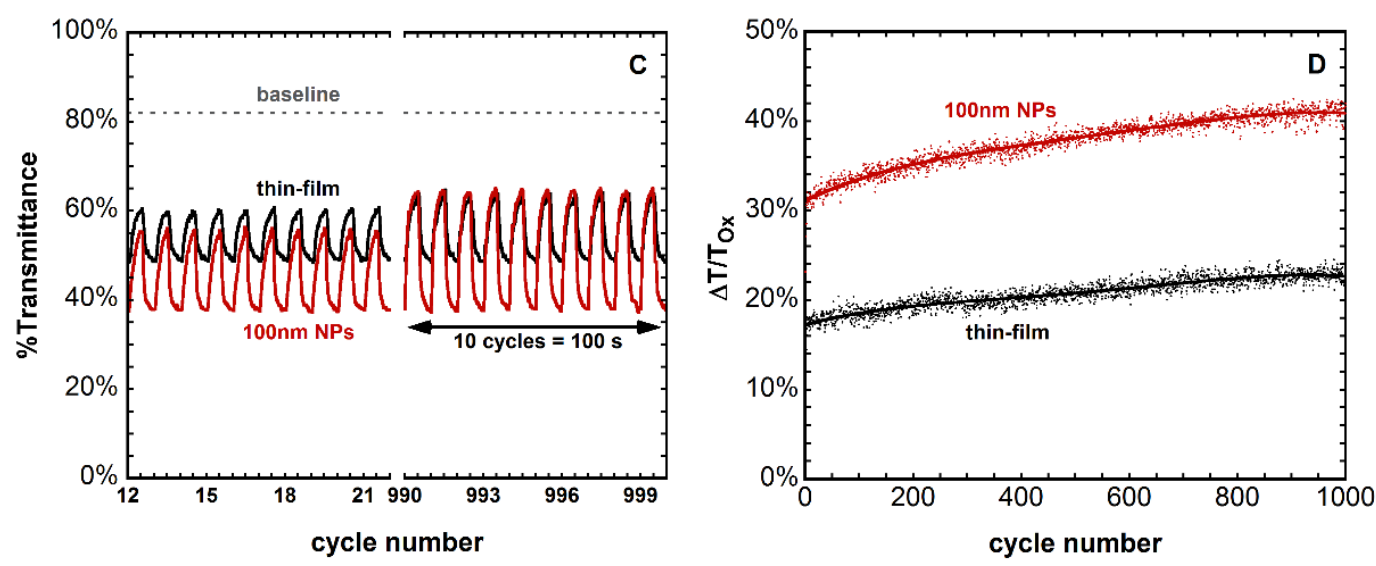

Figure 6 - (A) Comparison, in transmittance of the devices using P3HT thin-film and P3HT 100nm NPs, as prepared. (B) Comparison, in transmittance of the devices using P3HT thin-film and P3HT 100nm NPs, after 1000 cycles. (C) Changes in transmittance of P3HT thin-film and P3HT 100nm NPs devices during the cycling measurement and (D) Optical contrast evolution of the P3HT thin-film and P3HT 100nm NPs devices during the 1000 cycles performed. In all measurements, $1.5 \mathrm{~V}$ was used for Oxidation and $-1.5 \mathrm{~V}$ was used for reduction (1 cycle=10s).

For the freshly prepared devices, CE values are clearly higher for the device prepared with P3HT 100nm NPs. P3HT thin-films cast from chloroform solution show a normal value for P3HT (about $\left.124 \pm 3 \mathrm{~cm}^{2} \mathrm{C}^{-1}\right)$ but the P3HT films from water-dispersions of $100 \mathrm{~nm}$ NPs it is much higher $(180 \pm 2$ $\left.\mathrm{cm}^{2} \mathrm{C}^{-1}\right)$. As a comparison, the best reported value is $293.5 \mathrm{~cm}^{2} \mathrm{C}^{-1}$ using glass/ITO as substrate in a liquid state electrochemical cell. ${ }^{25}$ In this case, it is a completely sealed solid-state device without any annealing using PET/ITO as substrate (which has poor optical properties compared with glass/ITO).

Switching times and optical contrast are even more striking, a reduction switching of $4.4 \pm 0.6 \mathrm{~s}$ is reached. In the thin-film this value is much higher $(13.4 \pm 0.9 \mathrm{~s})$, indicating hindered kinetics for the thin-films. A full oxidation state is not reached in the thin-films, where the $\pi, \pi^{*}$ band is still intense at $-1.5 \mathrm{~V}$ (see Figures 4 and 5). Therefore, the use of nanoparticles facilitates a full oxidation of P3HT reducing the intensity of the $\pi, \pi^{*}$ band. This is crucial to obtain a higher color contrast and better switching times.

We performed a durability test by measuring absorption changes upon $10 \mathrm{~s}$ oxidation/reduction cycles $(1.5 /-1.5 \mathrm{~V})$ for 1000 cycles where 1 cycle $=10$ seconds. At that stage, the performance of the devices was measured again. Durability depends on several factors, such as the substrate used, the electrolyte and deposition method. A direct comparison with literature is not easy because of the number of variables that are in play, but for P3HT electrochromism values of about 1000 cycles are reported. ${ }^{26}$ In the present case no degradation was observed after 1000 cycles for both samples (Figure 5A), in 
fact, an increase of $\Delta \mathrm{Abs}$ appears. This points out to an electrochemical annealing of the films, where conformational changes give rise to better performances.

After 1000 cycles, the figures of merit were again calculated. The conclusions are the same, since the device with $100 \mathrm{~nm}$ NPs has a much better performance in terms of optical contrast (reaching almost $50 \%$ ) and $4 \mathrm{~s}$ switching times (Table 3). The thin-film also performs better, but still does not reach these values. $\mathrm{CE}$ at this stage is, interestingly, the same within experimental error.

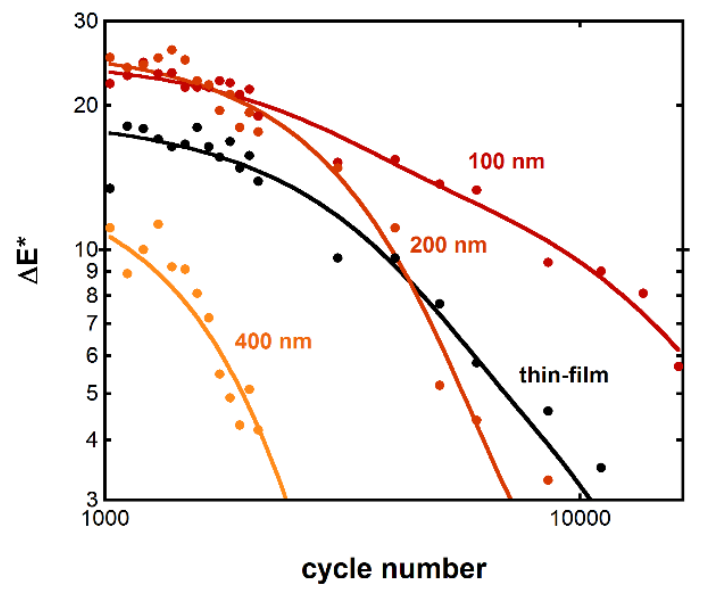

Figure 7 - Durability measurements performed in ECDs using P3HT thin-film, and different sized nanoparticles $(100 \mathrm{~nm}, 200 \mathrm{~nm}$ and $400 \mathrm{~nm})$. The results are presented in $\mathrm{L}^{*} \mathrm{a}^{*} \mathrm{~b}^{*}$ coordinates calculated using a ColorChecker ${ }^{\circledR}$ as reference.

Additionally, we tested the durability of different sized P3HT nanoparticles in electrochromic devices, 100nm, 200nm and 400nm in order to compare with P3HT spray-coated from chloroform solutions. In Figure 7 are presented the cycling measurements (in $\mathrm{L}^{*} \mathrm{a} \mathrm{b}^{*}$ coordinates), showing a trend in which larger sized P3HT nanoparticles present lower durability. 400nm P3HT nanoparticles have a strong decay, when the ECD stopped working around 3000cycles, 200nm nanoparticles present cyclability very similar to the thin-film ECDs prepared while the $100 \mathrm{~nm}$ NPs device presented longer durability with very poor electrochromic activity only around 15000 cycles. This result is very promising in terms of durability when P3HT is transformed in lower sized nanoparticles. Thus, we present durabilities over 10000cycles that, for optoelectronic applications is very interesting, comparing with previous durability tests made with the same polymer. ${ }^{26}$

Finally, it is worth noting that for POR the improved performance due to the use of nanoparticles film is also demonstrated, in particular by the increase in coloration efficiency (Table S3 and Figure S5). On the whole our data show that the availability of colloidal nanoparticles made of conjugated 
polymers deposited from water (or ethanol) is an environmentally sustainable strategy leading to electrochromic devices with improved properties.

\section{CONCLUSIONS.}

Using standard procedures currently employed in industrial applications we developed ECD prototypes from water dispersions of a classic polythiophene (P3HT), an approach that may be extended to different polythiophenes. Our approach offers very important advantages:

we avoid toxic organic solvents, such as chloroform during the electrochromic film deposition, ensuring the health safety of the user and reducing the environmental impact. This is particularly important for Do-It-Yourself kits ${ }^{45}$, in which anyone will be able to fabricate an electrochromic device at home

.ii) we observe enhanced performances with NPs ECDs. This enhancement confers faster switching times and shows a clear trend on higher durability. This is an extra and welcomed feature, which is crucial for industrial applications.

PEDOT formulations with PSS as water suspensions developed by Bayer in the later 1990's enabled their application in commercial products in the field of printed-electrochromics. ${ }^{10} \mathrm{We}$ think our approach will trigger a new progress in the industry by allowing a strong dissemination among designers and artists ${ }^{46-50}$ with the appearance of new-colors otherwise difficult to reach with metal oxides. Metal oxides are still the best option for smart windows and outdoors, but polymers allow a wider range of deposition techniques and color palette. Very beautiful colors were created in the last 20 years by researchers such as Reynold's group, ${ }^{10-12,51-55}$ but processability and stability was always an issue towards their commercialization. We hope this new approach will finally give a boost for electrochromic applications, definitely putting it in the roadmap of the internet-of-things that will develop in the incoming years.

\section{ACKNOWLEDGEMENTS}

EC is acknowledged for the INFUSION project grant N. 734834 under H2020-MSCA-RISE-2016. T.M., M.A., A.J.P. and C.A.T.L. were supported by LAQV-REQUIMTE, which is financed by the Portuguese FCT/MEC (UIDB/50006/2020). T.M. acknowledges PhD grant SFRH/BD/139171/2018 from FCT/MCTES. We are very grateful to Dr. Carlos Pinheiro and Ynvisible ${ }^{\circledR}$ company for discussions and assistance in the assembly of the electrochromic devices. 


\section{REFERENCES}

(1) Deb, S. K. A Novel Electrophotographic System. Appl. Opt. 1969, 8 (S1), 192.

(2) Paul M S Monk, R. J. M. \& D. R. R. Electrochromism: Terminology, Scope, Colouration. In Electrochromism; Wiley-VCH Verlag GmbH: Weinheim, Germany, 1995; pp 2-21.

(3) Mortimer, R. J.; Rosseinsky, D. R.; Monk, P. M. S. S. Electrochromic Materials and Devices; Mortimer, R. J., Rosseinsky, D. R., Monk, P. M. S., Eds.; Wiley-VCH Verlag GmbH \& Co. KGaA: Weinheim, Germany, 2013.

(4) Granqvist, C. G. Solar Energy Materials For Thermal Applications. In Kirk-Othmer Encyclopedia of Chemical Technology; John Wiley \& Sons, Inc.: Hoboken, NJ, USA, 2017; pp 1-28.

(5) Heeger, A. J. Charge Storage in Conducting Polymers: Solitons, Polarons, and Bipolarons. Polym. J. 1985, 17 (1), 201-208.

(6) Patil, A. O.; Heeger, A. J.; Wudl, F. Optical Properties of Conducting Polymers. Chem. Rev. 1988, $88(1), 183-200$.

(7) Pei, Q.; Zuccarello, G.; Ahlskog, M.; Inganäs, O. Electrochromic and Highly Stable Poly(3,4Ethylenedioxythiophene) Switches between Opaque Blue-Black and Transparent Sky Blue. Polymer (Guildf). 1994, 35 (7), 1347-1351.

(8) Rudge, A.; Davey, J.; Raistrick, I.; Gottesfeld, S.; Ferraris, J. P. Conducting Polymers as Active Materials in Electrochemical Capacitors. J. Power Sources 1994, 47 (1-2), 89-107.

(9) GUSTAFSSON, J.; LIEDBERG, B.; INGANAS, O. In Situ Spectroscopic Investigations of Electrochromism and Ion Transport in a Poly (3,4-Ethylenedioxythiophene) Electrode in a Solid State Electrochemical Cell. Solid State Ionics 1994, 69 (2), 145-152.

(10) Groenendaal, L.; Jonas, F.; Freitag, D.; Pielartzik, H.; Reynolds, J. R. Poly(3,4Ethylenedioxythiophene) and Its Derivatives: Past, Present, and Future. Adv. Mater. 2000, 12 (7), 481-494.

(11) Beaujuge, P. M.; Ellinger, S.; Reynolds, J. R. The Donor-Acceptor Approach Allows Ablackto-Transmissive Switching Polymeric Electrochrome. Nat. Mater. 2008, 7 (10), 795-799.

(12) Beaujuge, P. M.; Reynolds, J. R. Color Control in $\pi$-Conjugated Organic Polymers for Use in Electrochromic Devices. Chem. Rev. 2010, 110 (1), 268-320.

(13) Österholm, A. M.; Shen, D. E.; Gottfried, D. S.; Reynolds, J. R. Full Color Control and HighResolution Patterning from Inkjet Printable Cyan/Magenta/Yellow Colored-to-Colorless Electrochromic Polymer Inks. Adv. Mater. Technol. 2016, 1 (4), 1600063.

(14) Beverina, L.; Pagani, G. A.; Sassi, M. Multichromophoric Electrochromic Polymers: Colour Tuning of Conjugated Polymers through the Side Chain Functionalization Approach. Chem. Commun. 2014, 50 (41), 5413-5430.

(15) Sassi, M.; Salamone, M. M.; Ruffo, R.; Patriarca, G. E.; Mari, C. M.; Pagani, G. A.; Posset, U.; Beverina, L. State-of-the-Art Neutral Tint Multichromophoric Polymers for High-Contrast See-Through Electrochromic Devices. Adv. Funct. Mater. 2016, 26 (29), 5240-5246.

(16) Runnerstrom, E. L.; Llordés, A.; Lounis, S. D.; Milliron, D. J. Nanostructured Electrochromic Smart Windows: Traditional Materials and NIR-Selective Plasmonic Nanocrystals. Chem. Commun. 2014, 50 (73), 10555-10572. 
(17) Eh, A. L.-S.; Tan, A. W. M.; Cheng, X.; Magdassi, S.; Lee, P. S. Recent Advances in Flexible Electrochromic Devices: Prerequisites, Challenges, and Prospects. Energy Technol. 2018, 6 (1), 33-45.

(18) Chou, H.-H.; Nguyen, A.; Chortos, A.; To, J. W. F.; Lu, C.; Mei, J.; Kurosawa, T.; Bae, W.G.; Tok, J. B.-H.; Bao, Z. A Chameleon-Inspired Stretchable Electronic Skin with Interactive Colour Changing Controlled by Tactile Sensing. Nat. Commun. 2015, 6 (1), 8011.

(19) Kim, Y. Y.; Kim, Y. Y.; Kim, S.; Kim, E. Electrochromic Diffraction from Nanopatterned Poly(3-Hexylthiophene). ACS Nano 2010, 4 (9), 5277-5284.

(20) Barile, C. J.; Slotcavage, D. J.; McGehee, M. D. Polymer-Nanoparticle Electrochromic Materials That Selectively Modulate Visible and Near-Infrared Light. Chem. Mater. 2016, 28 (5), 1439-1445.

(21) Xing, X.; Zeng, Q.; Vagin, M.; Fahlman, M.; Zhang, F. Fast Switching Polymeric Electrochromics with Facile Processed Water Dispersed Nanoparticles. Nano Energy 2018, 47, 123-129.

(22) Costa, C.; Pinheiro, C.; Henriques, I.; Laia, C. A. T. Inkjet Printing of Sol-Gel Synthesized Hydrated Tungsten Oxide Nanoparticles for Flexible Electrochromic Devices. ACS Appl. Mater. Interfaces 2012, 4 (3), 1330-1340.

(23) Costa, C.; Pinheiro, C.; Henriques, I.; Laia, C. A. T. Electrochromic Properties of Inkjet Printed Vanadium Oxide Gel on Flexible Polyethylene Terephthalate/Indium Tin Oxide Electrodes. ACS Appl. Mater. Interfaces 2012, 4 (10), 5266-5275.

(24) Argun, A. A.; Aubert, P.-H.; Thompson, B. C.; Schwendeman, I.; Gaupp, C. L.; Hwang, J.; Pinto, N. J.; Tanner, D. B.; MacDiarmid, A. G.; Reynolds, J. R. Multicolored Electrochromism in Polymers: Structures and Devices. Chem. Mater. 2004, 16 (23), 4401-4412.

(25) Huang, J. H.; Yang, C. Y.; Hsu, C. Y.; Chen, C. L.; Lin, L. Y.; Wang, R. R.; Ho, K. C.; Chu, C. W. Solvent-Annealing-Induced Self-Organization of Poly(3-Hexylthiophene), a HighPerformance Electrochromic Material. ACS Appl. Mater. Interfaces 2009, 1 (12), 2821-2828.

(26) Kim, T.-H.; Choi, K.-I.; Kim, H.; Oh, S. H.; Koo, J.; Nah, Y.-C. Long-Term Cyclability of Electrochromic Poly(3-Hexyl Thiophene) Films Modified by Surfactant-Assisted Graphene Oxide Layers. ACS Appl. Mater. Interfaces 2017, 9 (23), 20223-20230.

(27) Pavlica, E.; Grubert, L.; Bratina, G.; Koch, N.; Samorì, P.; Orgiu, E.; Herder, M.; Crivillers, N.; Salleo, A.; Hecht, S.; et al. Optically Switchable Transistor via Energy-Level Phototuning in a Bicomponent Organic Semiconductor. Nat. Chem. 2012, 4 (8), 675-679.

(28) Millstone, J. E.; Kavulak, D. F. J.; Woo, C. H.; Holcombe, T. W.; Westling, E. J.; Briseno, A. L.; Toney, M. F.; Fréchet, J. M. J. Synthesis, Properties, and Electronic Applications of SizeControlled Poly(3-Hexylthiophene) Nanoparticles. Langmuir 2010, 26 (16), 13056-13061.

(29) Shimizu, H.; Yamada, M.; Wada, R.; Okabe, M. Preparation and Characterization of Water Self-Dispersible Poly(3-Hexylthiophene) Particles. Polym. J. 2008, 40 (1), 33-36.

(30) Zucchetti, E.; Zangoli, M.; Bargigia, I.; Bossio, C.; Di Maria, F.; Barbarella, G.; D’Andrea, C.; Lanzani, G.; Antognazza, M. R. Poly(3-Hexylthiophene) Nanoparticles for Biophotonics: Study of the Mutual Interaction with Living Cells. J. Mater. Chem. B 2017, 5 (3), 565-574.

(31) Brown, P.N.; Thomas, D.S.; Köhler, A.; Wilson, J. S.; Kim, J. S.; Ramsdale, C.M; Sirringhaus, H.; Friend, R.H. Effect of interchain interactions on the absorption and emission of poly(3- 
hexylthiophene). Phys. Rev. B, 2003, 67, 064203.

(32) Banerji, N.; Cowan, S.; Vauthey, E.; Heeger, A. J. Ultrafast Relaxation of the Poly(3Hexylthiophene) Emission Spectrum. J. Phys. Chem. C 2011, 115 (19), 9726-9739.

(33) Hestand, N.J.; Spano, F.C. Expanded Theory of H- and J-Molecular Aggregates: The Effects of Vibronic Coupling and Intermolecular Charge Transfer. Chem. Rev. 2018, 118 (15), 7069 7163.

(34) Warren, B. E. X-Ray Diffraction; Courier Corporation, 1990.

(35) Smilgies, D.-M. Scherrer Grain-Size Analysis Adapted to Grazing-Incidence Scattering with Area Detectors. J. Appl. Crystallogr. 2009, 42 (6), 1030-1034.

(36) Cook, S.; Furube, A.; Katoh, R. Analysis of the Excited States of Regioregular Polythiophene P3HT. Energy Environ. Sci. 2008, 1 (2), 294-299.

(37) Gomes, L.; Marques, A.; Branco, A.; Araújo, J.; Simões, M.; Cardoso, S.; Silva, F.; Henriques, I.; Laia, C. A. T.; Costa, C. IZO Deposition by RF and DC Sputtering on Paper and Application on Flexible Electrochromic Devices. Displays 2013, 34 (4), 326-333.

(38) Aliprandi, A.; Moreira, T.; Anichini, C.; Stoeckel, M.-A.; Eredia, M.; Sassi, U.; Bruna, M.; Pinheiro, C.; Laia, C. A. T.; Bonacchi, S.; et al. Hybrid Copper-Nanowire-Reduced-GrapheneOxide Coatings: A "Green Solution" Toward Highly Transparent, Highly Conductive, and Flexible Electrodes for (Opto)Electronics. Adv. Mater. 2017, 29 (41), 1703225.

(39) Fonseca, S. M.; Moreira, T.; Parola, A. J.; Pinheiro, C.; Laia, C. A. T. PEDOT Electrodeposition on Oriented Mesoporous Silica Templates for Electrochromic Devices. Sol. Energy Mater. Sol. Cells 2017, 159, 94-101.

(40) Di Maria, F.; Zanelli, A.; Liscio, A.; Kovtun, A.; Salatelli, E.; Mazzaro, R.; Morandi, V.; Bergamini, G.; Shaffer, A.; Rozen, S. Poly(3-Hexylthiophene) Nanoparticles Containing Thiophene- S , S -Dioxide: Tuning of Dimensions, Optical and Redox Properties, and Charge Separation under Illumination. ACS Nano 2017, 11 (2), 1991-1999.

(41) Gasiorowski, J.; Mardare, A. I.; Sariciftci, N. S.; Hassel, A. W. Electrochemical Characterization of Sub-Micro-Gram Amounts of Organic Semiconductors Using Scanning Droplet Cell Microscopy. J. Electroanal. Chem. 2013, 691, 77-82.

(42) Mahakul, P. C.; Mahanandia, P. Structural and Electrical Characteristics of Solution Processed P3HT-Carbon Nanotube Composite. IOP Conf. Ser. Mater. Sci. Eng. 2017, 178 (1), 012024.

(43) Monk, P.; Mortimer, R.; Rosseinsky, D. Electrochromism and Electrochromic Devices; Cambridge University Press: Cambridge, 2007.

(44) Hassab, S.; Shen, D. E.; Österholm, A. M.; Da Rocha, M.; Song, G.; Alesanco, Y.; Viñuales, A.; Rougier, A.; Reynolds, J. R.; Padilla, J. A New Standard Method to Calculate Electrochromic Switching Time. Sol. Energy Mater. Sol. Cells 2018, 185, 54-60.

(45) Müller, H.; Morais, S. Workshop on Transparent and Flexible Electrochromic Displays. 2019.

(46) Colley, A.; Woźniak, P. W.; Kiss, F.; Häkkilä, J. Shoe Integrated Displays. In Proceedings of the 10th Nordic Conference on Human-Computer Interaction - NordiCHI '18; ACM Press: New York, New York, USA, 2018; pp 39-46.

(47) Colley, A.; Hakala, L.; Harjuniemi, E.; Jarusriboonchai, P.; Müller, H.; Häkkilä, J. Exploring the Design Space of Electrochromic Displays. In Proceedings of the 8th ACM International 
Symposium on Pervasive Displays - PerDis '19; ACM Press: New York, New York, USA, 2019; pp 1-2.

(48) Jensen, W.; Löchtefeld, M.; Knoche, H. ShadowLamp. In Extended Abstracts of the 2019 CHI Conference on Human Factors in Computing Systems - CHI EA '19; ACM Press: New York, New York, USA, 2019; pp 1-6.

(49) Kololuoma, T.; Keranen, M.; Kurkela, T.; Happonen, T.; Korkalainen, M.; Kehusmaa, M.; Gomez, L.; Branco, A.; Ihme, S.; Pinheiro, C.; et al. Adopting Hybrid Integrated Flexible Electronics in Products: Case - Personal Activity Meter. IEEE J. Electron Devices Soc. 2019, $1-1$.

(50) Löchtefeld, M.; Jensen, W.; Müller, H.; Colley, A. Prototyping Transparent and Flexible Electrochromic Displays. In Extended Abstracts of the 2019 CHI Conference on Human Factors in Computing Systems - CHI EA '19; ACM Press: New York, New York, USA, 2019; pp 1-4.

(51) Kerszulis, J. A.; Johnson, K. E.; Kuepfert, M.; Khoshabo, D.; Dyer, A. L.; Reynolds, J. R. Tuning the Painter's Palette: Subtle Steric Effects on Spectra and Colour in Conjugated Electrochromic Polymers. J. Mater. Chem. C 2015, 3 (13), 3211-3218.

(52) Welsh, D. M.; Kumar, A.; Meijer, E. W.; Reynolds, J. R. Enhanced Contrast Ratios and Rapid Switching in Electrochromics Based on Poly(3,4-Propylenedioxythiophene) Derivatives. Adv. Mater. 1999, 11 (16), 1379-1382.

(53) Reeves, B. D.; Grenier, C. R. G.; Argun, A. A.; Cirpan, A.; McCarley, T. D.; Reynolds, J. R. Spray Coatable Electrochromic Dioxythiophene Polymers with High Coloration Efficiencies. Macromolecules 2004, 37 (20), 7559-7569.

(54) Amb, C. M.; Dyer, A. L.; Reynolds, J. R. Navigating the Color Palette of Solution-Processable Electrochromic Polymers. Chem. Mater. 2011, 23 (3), 397-415.

(55) Österholm, A. M.; Shen, D. E.; Kerszulis, J. A.; Bulloch, R. H.; Kuepfert, M.; Dyer, A. L.; Reynolds, J. R. Four Shades of Brown: Tuning of Electrochromic Polymer Blends toward High-Contrast Eyewear. ACS Appl. Mater. Interfaces 2015, 7 (3), 1413-1421. 